\title{
Everolimus in metastatic renal cell carcinoma patients intolerant to previous VEGFr-TKI therapy: a RECORD-I subgroup analysis
}

\author{
S Bracarda*, , TE Hutson ${ }^{2}$, C Porta $^{3}$, RA Figlin ${ }^{4}$, E Calvo5 ${ }^{5}$ V Grünwald ${ }^{6}$, A Ravaud ${ }^{7}$, R Motzer $^{8}$, D Kim $^{9}$, \\ O Anak ${ }^{10}$, A Panneerselvam "I and B Escudier ${ }^{12}$
}

'Ospedale San Donato USL8, Istituto Toscano Tumori (ITT), Via Pietro Nenni, 2052100 Arezzo, Italy; ${ }^{2}$ US Oncology/Baylor-Sammons Cancer Center, 3535 Worth Street, Dallas, TX 75246, USA; ${ }^{3}$ RCCS San Matteo University Hospital Foundation, Piazzale C. Golgi 19, Pavia I-27I 100, Italy; ${ }^{4}$ Samuel Oschin Comprehensive Cancer Institute, Cedars-Sinai Medical Center, 8700 Beverly Boulevard, AC 1085 North Tower, Los Angeles, CA 90048, USA; ${ }_{5}^{5}$ START Madrid, Centro Integral Oncológico Clara Campal, Hospital Madrid Norte Sanchinarro, 28050 Madrid, Spain; ${ }^{6}$ Medical School Hannover, Carl Neuberg Street I, D-30627 Hannover, Germany; ${ }^{7}$ Hôpital Saint André CHU, I rue Jean Burguet, 33075 Bordeaux, France; ${ }^{8}$ Memorial SloanKettering Cancer Center, 1275 York Avenue, New York, NY 10021 , USA; ${ }^{9}$ Novartis Oncology Global Medical Affairs, One Health Plaza, East Hanover, NJ 07936, USA; ${ }^{10}$ Novartis Oncology Global Development, CH-4002 Basel, Switzerland; "Novartis Oncology Biometrics and Data Management, 180 Park Avenue, Florham Park, NJ 07936, USA; ${ }^{2}$ Institut Gustave Roussy, I I 4 rue Edouard Vaillant, 94805 Villejuif, France

\begin{abstract}
BACKGROUND: A relevant percentage of patients with metastatic renal cell carcinoma develop intolerance to vascular endothelial growth factor receptor-tyrosine kinase inhibitors (VEGFr-TKIs) and require careful selection of subsequent treatment. This retrospective analysis evaluated the safety and efficacy of everolimus in patients enrolled in the phase-III RECORD-I trial who discontinued previous VEGFr-TKI therapy because of toxicity.

METHODS: Patients with an adverse event (AE) as their primary reason for discontinuation of previous VEGFr-TKI therapy were included. Median progression-free survival (PFS) for VEGFr-TKI-intolerant patients in each arm was estimated using the Kaplan-Meier method, and effect on PFS (hazard ratio $(H R)$ ) was calculated using the Cox proportional hazard model.

RESULTS: In VEGFr-TKI-intolerant patients ( $n=58,14 \%$ ), median PFS was 5.4 months with everolimus and 1.9 months with placebo (HR: 0.32; $P=0.004)$. In sunitinib-intolerant patients $(n=26)$, median PFS was 5.1 months with everolimus and 2.8 months with placebo (HR: 0.28; $P=0.033)$. Grade 3/4 AEs reported with everolimus in VEGFr-TKI-intolerant patients included infections (I6\%), fatigue (7\%) and stomatitis (4\%). The toxicity profile of everolimus was similar in the VEGFr-TKI-intolerant and overall study populations.

CONCLUSION: Everolimus is well tolerated and efficacious with no increased toxicity in patients intolerant to VEGFr-TKI therapy. British Journal of Cancer (2012) 106, 1475- |480. doi:I0.1038/bjc.2012.89 www.bjcancer.com
\end{abstract}

Published online 22 March 2012

(c) 2012 Cancer Research UK

Keywords: intolerance; kidney cancer; mTOR inhibitor; RAD00 I; VEGF-targeted therapy

Sequential treatment with targeted therapies is the current standard of care for patients with metastatic renal cell carcinoma (mRCC) (de Reijke et al, 2009; Escudier and Kataja, 2010; Ljungberg et al, 2010; National Comprehensive Cancer Network, 2012). Targeted therapies approved for use in patients with mRCC include the anti-vascular endothelial growth factor (VEGF) monoclonal antibody bevacizumab, the VEGF receptor-tyrosine kinase inhibitors (VEGFr-TKIs) sorafenib, sunitinib and pazopanib, and the mammalian target of rapamycin (mTOR) inhibitors everolimus and temsirolimus.

First-line systemic treatment options supported by the highest level of clinical evidence for patients with mRCC are the VEGFtargeted agents sunitinib, pazopanib and bevacizumab (plus interferon- $\alpha$ ) for patients of good or intermediate Memorial Sloan-Kettering Cancer Center (MSKCC) risk and the mTOR

\footnotetext{
*Correspondence: Dr S Bracarda;
}

E-mail: sergio.bracarda@usl8.toscana.it

Received 31 October 2011; revised 17 February 2012; accepted 22 February 2012; published online 22 March 2012 inhibitor temsirolimus for patients of poor MSKCC risk (de Reijke et al, 2009; Escudier and Kataja, 2010; Ljungberg et al, 2010; National Comprehensive Cancer Network, 2012). Although many patients obtain significant clinical benefit in terms of progressionfree survival (PFS) from treatment with VEGF-targeted therapies, these agents are not well tolerated by all patients, leading to treatment discontinuation in a relevant percentage of cases.

Adverse events (AEs) commonly observed in patients treated with VEGFr-TKIs include hypertension, hand-foot skin reaction (palmoplantar erythrodysesthesia), rash/desquamation, alopecia, diarrhoea, fatigue, hyponatremia, neutropenia and thrombocytopenia (Ravaud, 2011). The onset of treatment-related AEs may necessitate dose interruptions, dose adjustments and/or treatment discontinuation in some patients. In a phase-III trial of patients with mRCC treated with sunitinib $(n=375)$ or interferon- $\alpha$ $(n=375), 8 \%$ and $13 \%$ of patients, respectively, discontinued treatment because of AEs (Motzer et al, 2007). In the phase-III TARGET trial of patients with mRCC receiving sorafenib $(n=451)$ or placebo $(n=452), 21 \%$ of sorafenib-treated patients required dose interruptions primarily because of the occurrence of handfoot skin reaction, whereas $6 \%$ of patients in the placebo group 
required dose interruptions (Escudier et al, 2007). In a phase-III study of patients with mRCC who received pazopanib $(n=290)$ or placebo $(n=145), 14 \%$ and $3 \%$ of patients, respectively, discontinued treatment because of AEs (Sternberg et al, 2010). Tolerability of first-line VEGFr-TKIs may be an even more relevant issue in clinical practice compared with clinical trials (Choueiri et al, 2010; Porta et al, 2011b). Results of two retrospective chart reviews from tertiary oncology centres in the United States (Choueiri et al, 2010) and Italy (Porta et al, 2011b) found that $26-37 \%$ of patients treated with first-line sunitinib or sorafenib required dose reductions because of AEs, $19-32 \%$ of patients required dose interruptions because of AEs and $5-18 \%$ discontinued treatment because of AEs.

For patients who are intolerant to first-line VEGF-targeted therapy (i.e., discontinue therapy because of unacceptable toxicity), careful selection of second-line treatment is particularly critical in order to achieve maximum clinical benefit while minimising the occurrence of further treatment-related AEs. VEGF-targeted agents and mTOR inhibitors have distinct class effect toxicities (Ravaud, 2011); thus, patients who are intolerant to first-line VEGF-targeted therapy may be less likely to experience significant toxicity with a second-line mTOR inhibitor than a second-line VEGF-targeted agent. The phase-III RECORD-1 study evaluated the efficacy of the oral mTOR inhibitor everolimus in patients with mRCC whose disease had progressed on, or who were intolerant to, previous VEGFr-TKI therapy (sunitinib and/or sorafenib) (Motzer et al, 2008, 2010). Median PFS was prolonged from 1.9 months (95\% CI: $1.8-1.9$ ) to 4.9 months (95\% CI: $4.0-$ 5.5) for patients who received placebo or everolimus, respectively (Motzer et al, 2010). Risk of disease progression was reduced by $67 \%$ for patients in the everolimus group, compared with patients in the placebo group (hazard ratio (HR): 0.33; $P<0.001$ ). Based on these results, current clinical practice guidelines recommend everolimus as the standard of care for patients with mRCC who have failed initial VEGFr-TKI therapy (de Reijke et al, 2009; Escudier and Kataja, 2010; Ljungberg et al, 2010; National Comprehensive Cancer Network, 2012).

Herein we present the results of a retrospective analysis of RECORD-1 that evaluated the efficacy and safety of everolimus in the subgroup of patients who discontinued previous VEGFr-TKI therapy because of toxicity.

\section{MATERIALS AND METHODS}

\section{Patient population}

The study design of RECORD-1, an international, multicentre, double-blind, randomised phase-III trial, has been previously reported (Motzer et al, 2008). Adult patients (aged $\geqslant 18$ years) with measurable clear cell mRCC (according to RECIST 1.0 (Therasse et al, 2000)), which had progressed within 6 months of stopping treatment with sunitinib, sorafenib or both were included in the study. Previous treatment with bevacizumab, interleukin 2 or interferon- $\alpha$ also was permitted. Other key inclusion criteria were a Karnofsky performance status of at least $70 \%$ (scale $0-100$, higher scores indicated better performance) and adequate bone marrow, hepatic and renal function. Patients in all MSKCC-risk categories (favourable, intermediate and poor) were included. Key exclusion criteria were previous treatment with temsirolimus, untreated central nervous system metastases and uncontrolled medical conditions (e.g., unstable angina pectoris, symptomatic congestive heart failure, recent myocardial infarction or diabetes).

\section{Study treatments}

Patients were stratified according to whether they received one or two previous VEGFr-TKIs and by MSKCC-risk group. Patients were then randomly assigned $2: 1$ to receive either continuous treatment with oral everolimus $10 \mathrm{mg}$ once daily $(n=277)$ or placebo $(n=139)$, both in conjunction with best supportive care (Motzer et al, 2010). A cycle was 28 days of treatment. Doses were delayed or reduced (to $5 \mathrm{mg}$ once daily) if patients had clinically significant haematological or other AEs that were considered by the investigator to be related to everolimus. Treatment continued until disease progression, unacceptable toxicity, death or discontinuation for any other reason. Patients randomly assigned to placebo who experienced disease progression were permitted to cross over to open-label everolimus.

\section{Assessments}

The primary reason for discontinuation of each previous antineoplastic therapy (AE, disease progression or other) was collected for all patients. Patients for whom an AE was the primary reason for discontinuation of previous sunitinib therapy, sorafenib therapy or both (i.e., discontinuation of previous VEGFr-TKI therapy because of unacceptable toxicity) were included in this subgroup analysis and assessed for PFS and safety. PFS was defined as the time from randomisation to the first documentation of disease progression or death from any cause and was documented according to RECIST 1.0 and assessed via blinded, independent central review (Motzer et al, 2008). Tumour measurements were assessed by CT or MRI scans and were performed at screening and every 8 weeks thereafter.

Safety was assessed in all patients who received at least one dose of study drug. AEs and laboratory evaluations were monitored and graded according to the National Cancer Institute's Common Terminology Criteria for AEs, version 3.0 (National Cancer Institute, 2006). Vital signs were measured, physical examinations were performed and all concomitant medications and therapies were recorded.

\section{Analysis}

The Kaplan-Meier method was used to estimate median PFS for patients intolerant to previous VEGFr-TKI therapy in each treatment arm and the Cox proportional hazard model was used to calculate the HR of treatment effect on PFS.

\section{Ethical conduct}

RECORD-1 was conducted according to the ethical principles of the Declaration of Helsinki. The study protocol was reviewed by the independent ethics committee or institutional review board for each centre. Each patient provided written informed consent before screening procedures were initiated.

\section{RESULTS}

In the overall RECORD-1 population, $14 \%$ of patients $(n=58)$ discontinued previous VEGFr-TKI therapy because of unacceptable toxicity. Among the subgroup of 58 patients who were intolerant to previous VEGFr-TKI therapy, 45 patients and 13 patients were randomly assigned to everolimus and placebo, respectively. Baseline characteristics in this subgroup of patients were generally similar to those of the overall study population; however, some differences between placebo-treated patients who were VEGFr-TKI-intolerant and all placebo-treated patients were noted (e.g., younger median age and higher percentage of women) (Table 1). When stratified by previous VEGFr-TKI therapy, of the 45 patients who received everolimus, 21 were intolerant to previous sunitinib, 19 were intolerant to previous sorafenib and 5 were intolerant to previous sunitinib and sorafenib. Of the 
Everolimus in VEGFr-TKI-intolerant patients with $\mathrm{mRCC}$

Table I Patient demographics in the subgroup of patients who were intolerant of previous VEGFr-TKI therapy and all patients in the RECORD-I trial

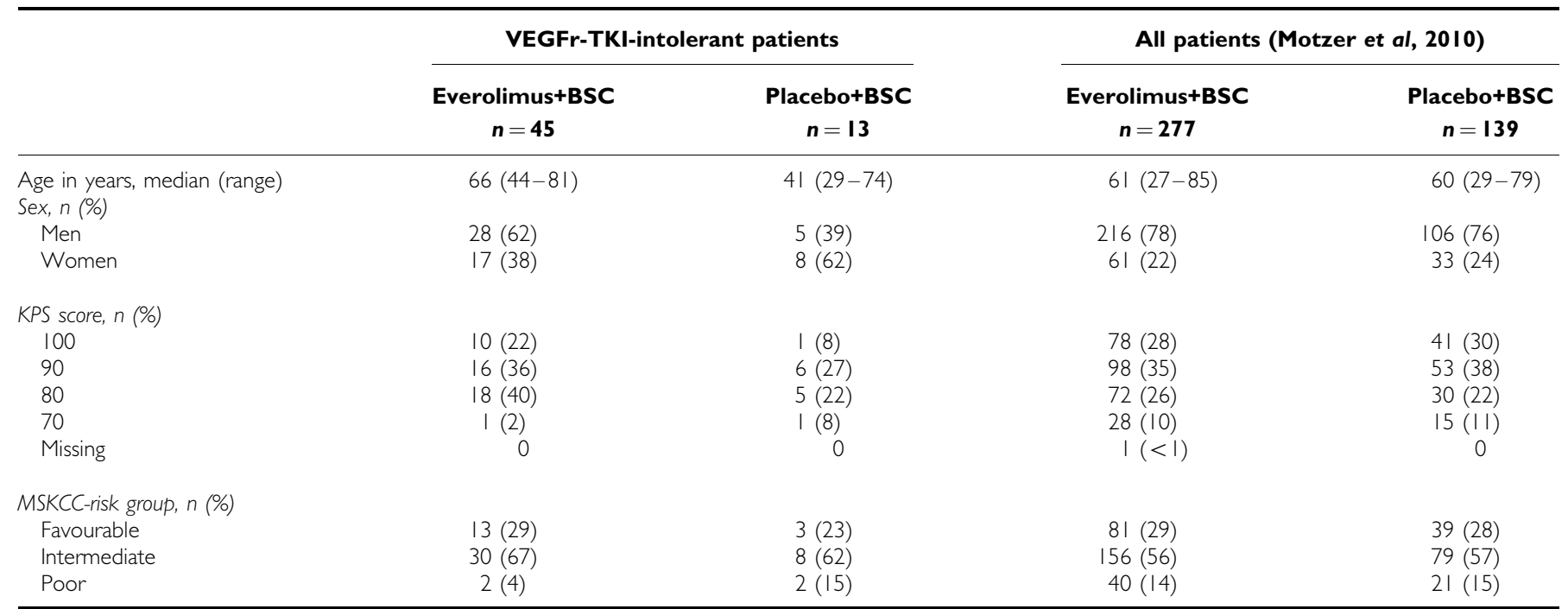

Abbreviations: BSC = best supportive care; KPS = Karnofsky performance status; MSKCC = Memorial Sloan-Kettering Cancer Center; VEGFr-TKI = vascular endothelial growth factor receptor-tyrosine kinase inhibitor.

Table 2 Rates and reasons for discontinuation of everolimus or placebo in patients who were intolerant of previous VEGFr-TKI therapy

\begin{tabular}{lcc}
\hline Discontinuations, $\boldsymbol{n}(\%)$ & $\begin{array}{c}\text { Everolimus+BSC } \\
\mathbf{n}=\mathbf{4 5}\end{array}$ & $\begin{array}{c}\text { Placebo+BSC } \\
\mathbf{n}=\mathbf{I 3}\end{array}$ \\
\hline Reason for discontinuation, $n(\%)$ & $30(66.7)$ & $12(92.3)$ \\
Disease progression & $19(42.2)$ & $11(84.6)$ \\
Adverse event & $6(13.3)$ & 0 \\
Consent withdrawn & $3(6.7)$ & 0 \\
Abnormal laboratory value & $1(2.2)$ & 0 \\
Lost to follow-up & $1(2.2)$ & 0 \\
Death & 0 & $\mid(7.7)$ \\
\hline
\end{tabular}

Abbreviations: BSC = best supportive care; VEGFr-TKI = vascular endothelial growth factor receptor-tyrosine kinase inhibitor.

13 patients who received placebo, 5 were intolerant to previous sunitinib and 8 were intolerant to previous sorafenib.

Among patients who were intolerant to previous VEGFr-TKI therapy and subsequently received everolimus or placebo, $42.2 \%$ and $84.6 \%$, respectively, discontinued treatment because of disease progression, whereas $13 \%$ and $0 \%$, respectively, discontinued treatment because of AEs (Table 2). AEs that led to discontinuation of everolimus treatment were asthenia, increased blood creatinine, dehydration, dyspnoea, increased gamma-glutamyltransferase, general physical health deterioration, pathological fracture, pleural effusion and pneumonitis.

As was observed in the overall RECORD-1 population, everolimus significantly prolonged PFS compared with placebo in patients who were intolerant to previous VEGFr-TKI therapy (Figure 1). Median PFS was 5.4 months (95\% CI: 3.8-5.9) with everolimus and 1.9 months ( $95 \%$ CI: $1.8-3.7$ ) with placebo. Risk of disease progression was decreased by $68 \%$ with everolimus compared with placebo (HR: 0.32 ; $95 \%$ CI: $0.13-0.77 ; P=0.004$ ).

PFS benefit of everolimus compared with placebo was similar for patients who were intolerant to previous sunitinib or sorafenib therapy (Table 3). Among patients who were intolerant to previous sunitinib therapy, median PFS was 5.1 months (95\% CI: 3.7-not available) with everolimus and 2.8 months (95\% CI: 1.9-3.7) with placebo (HR: 0.28 ; 95\% CI: $0.07-1.18 ; P=0.033$ ). Among patients who were intolerant to previous sorafenib therapy, median PFS was 5.6 months
A

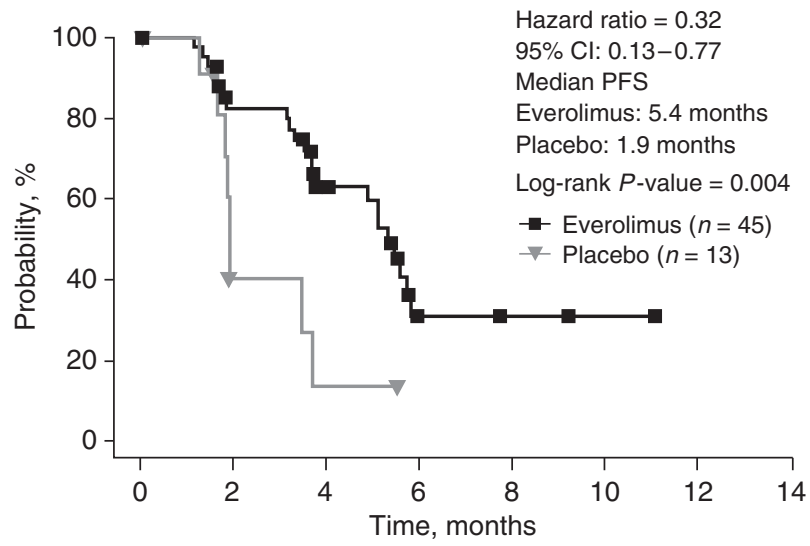

Number of patients at risk

$\begin{array}{lllllllll}\text { Everolimus } & 45 & 31 & 19 & 5 & 4 & 1 & 0 & 0\end{array}$

$\begin{array}{lllllllll}\text { Placebo } & 13 & 3 & 1 & 0 & 0 & 0 & 0 & 0\end{array}$

B



Number of patients at risk

$\begin{array}{lllllllll}\text { Everolimus } & 277 & 192 & 115 & 51 & 26 & 10 & 1 & 0 \\ \text { Placebo } & 139 & 47 & 15 & 6 & 2 & 0 & 0 & 0\end{array}$

Figure I Kaplan-Meier estimates of PFS by treatment group in the patients intolerant of previous VEGFr-TKI therapy (A) and the overall RECORD-I population (B) (Motzer et al, 20 I0). Figure IB was reprinted from Motzer et al, 20 I0, copyright (20 I0), with permission from John Wiley \& Sons (Hoboken, NJ, USA). Abbreviations: PFS = progression-free survival; VEGFr$T K I=$ vascular endothelial growth factor receptor-tyrosine kinase inhibitor. 
Table 3 PFS in patients intolerant to previous sunitinib and/or sorafenib therapy

\begin{tabular}{|c|c|c|c|c|}
\hline & \multicolumn{2}{|c|}{ Intolerant to previous sunitinib ${ }^{a}$} & \multicolumn{2}{|c|}{ Intolerant to previous sorafenib ${ }^{b}$} \\
\hline & Everolimus+BSC & Placebo+BSC & Everolimus+BSC & Placebo+BSC \\
\hline
\end{tabular}

Abbreviations: $\mathrm{BSC}=$ best supportive care; $\mathrm{Cl}=$ confidence interval; $\mathrm{NA}=$ not available; PFS = progression-free survival. ${ }^{\text {a }}$ Patients who had an adverse event (AE) as the primary reason for discontinuation of previous sunitinib. Patients may have also received previous sorafenib. ${ }^{b}$ Patients who had an $A E$ as the primary reason for discontinuation of previous sorafenib. Patients may have also received previous sunitinib. ${ }^{\circ}$ Of the 45 VEGFr-TKI-intolerant patients randomly assigned to everolimus, 5 patients were intolerant to both previous sunitinib and sorafenib and were included in both previous treatment groups.

Table 4 Commonly reported adverse events and laboratory abnormalities, irrespective of relation to treatment, in patients intolerant to previous VEGFr-TKI therapy and the overall RECORD-I population

\begin{tabular}{|c|c|c|c|c|c|c|c|c|c|c|c|c|}
\hline & \multicolumn{6}{|c|}{ Patients intolerant to previous VEGFr-TKI therapy } & \multicolumn{6}{|c|}{ All patients (Motzer et al, 20l0) } \\
\hline \multicolumn{13}{|l|}{ Adverse event, \% } \\
\hline Stomatitis ${ }^{\mathrm{a}}$ & 49 & 4 & 0 & 15 & 0 & 0 & 44 & 4 & $<1$ & 8 & 0 & 0 \\
\hline Diarrhoea & 31 & 2 & 0 & 0 & 0 & 0 & 30 & 1 & 0 & 7 & 0 & 0 \\
\hline Rash & 31 & 0 & 0 & 0 & 0 & 0 & 29 & I & 0 & 7 & 0 & 0 \\
\hline Nausea & 27 & 0 & 0 & 23 & 0 & 0 & 26 & 1 & 0 & 19 & 0 & 0 \\
\hline Asthenia & 24 & 2 & 0 & 23 & 0 & 0 & 33 & 3 & $<1$ & 23 & 4 & 0 \\
\hline Peripheral oedema & 24 & 0 & 0 & 15 & 0 & 0 & 25 & $<1$ & 0 & 8 & $<1$ & 0 \\
\hline Mucosal inflammation & 16 & 2 & 0 & 0 & 0 & 0 & 19 & । & 0 & । & 0 & 0 \\
\hline Lymphocytes decreased & 64 & 18 & 2 & 31 & 0 & 0 & 51 & 16 & 2 & 28 & 5 & 0 \\
\hline Creatinine increased & 60 & 0 & 0 & 31 & 0 & 0 & 50 & 1 & 0 & 34 & 0 & 0 \\
\hline Platelets decreased & 40 & 0 & 2 & 8 & 0 & 8 & 23 & 1 & 0 & 2 & 0 & $<1$ \\
\hline
\end{tabular}

Abbreviations: BSC = best supportive care; VEGFr-TKI = vascular endothelial growth factor receptor-tyrosine kinase inhibitor. ${ }^{a}$ Stomatitis (including aphthous stomatitis), mouth ulceration and tongue ulceration. ${ }^{b}$ All infections reported, including pneumonia, aspergillosis, candidiasis and sepsis.

(95\% CI: 3.8 - not available) with everolimus and 1.9 months (95\% CI: $1.7-3.5$ ) with placebo (HR: $0.29 ; 95 \%$ CI: $0.09-0.91 ; P=0.012$ ).

Everolimus was generally well tolerated in patients who were intolerant to previous VEGFr-TKI therapy, with low rates of grade 3 and grade $4 \mathrm{AEs}$, and the safety profile was similar to that observed in the overall RECORD-1 population (Table 4). In the everolimus cohort of patients intolerant to previous VEGFr-TKI therapy, the most common AEs (all grade and grade $\geqslant 3$ incidence, respectively) were stomatitis ( $49 \%$ and $4 \%)$, fatigue $(38 \%$ and $7 \%$ ) and infections (33\% and $16 \%)$, and the most commonly reported grade $\geqslant 3$ laboratory abnormalities were hyperglycaemia $(20 \%)$, lymphopenia (20\%) and anaemia (15\%).

\section{DISCUSSION}

Targeted therapies in mRCC are rarely curative, and patients often rely on multiple lines of therapy to derive sustained clinical benefit (Oudard and Elaidi, 2012). In patients with mRCC who are intolerant to first-line VEGF-targeted therapy and must discontinue treatment before disease progression, tolerability of subsequent therapy is of particular importance. Patients who require dose reductions/interruptions or cessation of treatment to manage toxicity associated with VEGF-targeted therapy may experience reduced efficacy of that agent. A recent pharmacokinetic/ pharmacodynamic meta-analysis of sunitinib-treated patients with various types of cancer, including $\mathrm{mRCC}$, demonstrated a positive relationship between drug exposure and time to progression or overall survival (Houk et al, 2010). However, increased sunitinib exposure was also associated with increased incidence of classeffect toxicities such as hypertension, neutropenia and fatigue.

In previous studies of sequential administration of VEGFtargeted agents, overlapping toxicity profiles of these agents have resulted in high incidences of certain treatment-related AEs, such as hypertension, skin toxicities, fatigue and gastrointestinal toxicities, some of which have required dose modifications (Rini et al, 2008, 2011; Di Lorenzo et al, 2009; Garcia et al, 2010). The AXIS phase-III trial evaluated the safety and efficacy of axitinib $v s$ sorafenib in patients with mRCC who had failed firstline treatment with a sunitinib-, bevacizumab-, temsirolimus- or cytokine-based regimen; $62 \%$ of patients received first-line VEGFtargeted therapy (sunitinib or bevacizumab) (Rini et al, 2011). In the overall AXIS population, class-effect AEs reported in the axitinib and sorafenib arms included diarrhoea (55\% and 53\%, respectively), hypertension ( $40 \%$ and $29 \%$, respectively), fatigue (39\% and $32 \%$, respectively), palmar-plantar erythrodysaesthesia 
( $27 \%$ and $51 \%$, respectively), rash ( $13 \%$ and $32 \%$, respectively) and alopecia (4\% and $32 \%$, respectively) (Rini et al, 2011). One or more dose reduction was reported in $31 \%$ and $52 \%$ of patients in the axitinib and sorafenib arms, respectively, and $77 \%$ and $80 \%$ of patients in each arm, respectively, had one or more dose interruption (Rini et al, 2011). Safety data for the subgroup of patients who failed previous VEGFr-TKI therapy (54\%) has yet to be reported.

The safety profile of mTOR inhibitors generally does not overlap with that of VEGFr-TKIs (Escudier et al, 2007; Motzer et al, 2007, 2010), thus, patients who experience intolerance to VEGFr-TKI therapy may benefit from switching to an mTOR inhibitor. Most common grade $\geqslant 3$ AEs with everolimus in the overall RECORD-1 population were infections (10\%), dyspnoea (7\%), fatigue $(5 \%)$ and stomatitis $(\sim 5 \%)$, and most common grade $\geqslant 3$ laboratory abnormalities were lymphopenia $(18 \%)$, hyperglycaemia $(\sim 16 \%)$ and anaemia (13\%) (Motzer et al, 2010). Noninfectious pneumonitis, a class effect of mTOR inhibitors, was reported in $13.5 \%$ of patients in the everolimus group of the RECORD-1 study (grade 1, $3.3 \%$; grade 2, 6.6\%; grade 3, 3.6\%; and grade 4, $0 \%$ ) (Motzer et al, 2010; White et al, 2010; Porta et al, 2011a). Cardiovascular toxicity (hypertension, reduced left ventricular ejection fraction, cardiac ischaemia and infarction) and hand-foot skin reaction are not commonly observed in patients treated with everolimus (Escudier et al, 2007; Motzer et al, 2007, 2010).

Results of this subgroup analysis of RECORD-1 demonstrate that everolimus is well tolerated and efficacious in patients who are intolerant to VEGFr-TKI therapy. VEGFr-TKI-intolerant patients, who may be at risk for experiencing treatment-related AEs, did not experience increased toxicity and, notably, did not experience increased rates of pneumonitis relative to the overall RECORD-1 population (Motzer et al, 2010). In this analysis, $13.3 \%$ of patients discontinued treatment with everolimus because of AEs, thus, the majority $(86.7 \%)$ of VEGFr-TKI-intolerant patients did tolerate treatment with everolimus. Additionally, the median PFS of everolimus in patients who were intolerant to previous VEGFr-TKI therapy (5.4 months) was similar to the median PFS of all everolimus-treated patients in RECORD-1 (4.9 months) (Motzer et al, 2010).

The retrospective nature of this analysis, small sample size, and lack of patient stratification within the subgroup suggest use of caution when interpreting these results. Furthermore, this analysis was not powered or designed to enable statistical comparison of efficacy or safety profiles between patients intolerant to VEGFr-TKI therapy and the overall RECORD-1 population. Further studies of everolimus in patients intolerant to VEGFtargeted therapy are warranted to confirm our observations.

Recent evidence has indicated that sequential treatment with a VEGFr-TKI and an mTOR inhibitor may permit eventual rechallenge with a third-line VEGFr-TKI. A subset of RECORD-1 patients from French sites $(n=36)$ demonstrated a median PFS of 5.3 months for sorafenib, 8 months for sunitinib and 12 months for dovitinib (TKI258) after disease progression on at least one VEGFr-TKI and everolimus (Blesius et al, 2010). Another subset of RECORD-1 patients from a German institution $(n=39)$ achieved a median PFS of 5.1 months after receiving sorafenib, sunitinib or dovitinib following previous treatment with at least one VEGFrTKI and everolimus (Gruenwald et al, 2010). In a retrospective Italian study $(n=34)$, third-line sorafenib after sequential therapy with sunitinib followed by everolimus or temsirolimus was associated with a median PFS of 4 months and a median overall survival of 7 months from initiation of sorafenib treatment (Di Lorenzo et al, 2010). A phase-III study designed to compare the safety and efficacy of dovitinib and sorafenib in patients with mRCC whose disease has progressed on one previous VEGFr-TKI and one previous mTOR inhibitor is currently ongoing (ClinicalTrials.gov identifier: NCT01223027).

In conclusion, appropriate selection of second-line therapy to maximise clinical benefit and minimise the occurrence of treatment-related AEs for patients who are intolerant of initial VEGF-targeted therapy is a key clinical issue. Results of this subgroup analysis of the phase-III RECORD-1 study demonstrate that everolimus can be safely given to patients with a previous intolerance to VEGFr-TKI therapy. These results further support everolimus as the treatment of choice in patients who have failed initial VEGFr-TKI therapy.

\section{ACKNOWLEDGEMENTS}

Editorial assistance was provided by ApotheCom, Yardley, PA, USA, and funded by Novartis Pharmaceuticals Corporation.

\section{REFERENCES}

Blesius A, Beuselinck B, Chevreau C, Ravaud A, Rolland F, Oudard S, Escudier B (2010) Are TKIs still active in patients treated with TKI and everolimus? Experience from 36 patients treated in France in the RECORD 1 trial. Ann Oncol 21(Suppl 8): viii284 (Abstract 908P)

Choueiri TK, Duh MS, Clement J, Brick AJ, Rogers MJ, Kwabi C, Shah K, Percy AG, Antras L, Jayawant SS, Chen K, Wang ST, Luka A, Neary MP, McDermott D, Oh WK (2010) Angiogenesis inhibitor therapies for metastatic renal cell carcinoma: effectiveness, safety and treatment patterns in clinical practice-based on medical chart review. BJU Int 105: $1247-1254$

de Reijke TM, Bellmunt J, van Poppel H, Marreaud S, Aapro M (2009) EORTC-GU group expert opinion on metastatic renal cell cancer. Eur J Cancer 45: 765 -773

Di Lorenzo G, Carteni G, Autorino R, Bruni G, Tudini M, Rizzo M, Aieta M, Gonnella A, Rescigno P, Perdona S, Giannarini G, Pignata S, Longo N, Palmieri G, Imbimbo C, De Laurentiis M, Mirone V, Ficorella C, De Placido S (2009) Phase II study of sorafenib in patients with sunitinibrefractory metastatic renal cell cancer. J Clin Oncol 27: 4469-4474

Di Lorenzo G, Buonerba C, Federico P, Rescigno P, Milella M, Ortega C, Aieta M, D'Aniello C, Longo N, Felici A, Ruggeiri EM, Palmieri G, Imbimbo C, Aglietta M, De Placido S, Mirone V (2010) Third-line sorafenib after sequential therapy with sunitinib and mTOR inhibitors in metastatic renal cell carcinoma. Eur Urol 58: 906-911
Escudier B, Eisen T, Stadler WM, Szczylik C, Oudard S, Siebels M, Negrier S, Chevreau C, Solska E, Desai AA, Rolland F, Demkow T, Hutson TE, Gore M, Freeman S, Schwartz B, Shan M, Simantov R, Bukowski RM, for the TARGET Study Group (2007) Sorafenib in advanced clear-cell renal-cell carcinoma. $N$ Engl J Med 356: $125-134$

Escudier B, Kataja V (2010) Renal cell carcinoma: ESMO Clinical practice guidelines for diagnosis, treatment and follow-up. Ann Oncol 21(Suppl 5): v137-v139

Garcia JA, Hutson TE, Elson P, Cowey CL, Gilligan T, Nemec C, Dreicer R, Bukowski RM, Rini BI (2010) Sorafenib in patients with metastatic renal cell carcinoma refractory to either sunitinib or bevacizumab. Cancer 116: $5383-5390$

Gruenwald V, Seidel C, Fenner M, Heuser M, Ganser A (2010) Antitumor activity of tyrosine kinase inhibitors (TKI) after failure of RAD001 in metastatic renal cell carcinoma (mRCC). Presented at the 2010 ASCO Genitourinary Cancers Symposium, 5-7 March 2010, San Francisco, CA, USA (Abstract 414)

Houk BE, Bello CL, Poland B, Rosen LS, Demetri GD, Motzer RJ (2010) Relationship between exposure to sunitinib and efficacy and tolerability endpoints in patients with cancer: results of a pharmacokinetic/ pharmacodynamic meta-analysis. Cancer Chemother Pharmacol 66: $357-371$ 
Ljungberg B, Cowan NC, Hanbury DC, Hora M, Kuczyk MA, Merseburger AS, Patard JJ, Mulders PF, Sinescu IC (2010) EAU guidelines on renal cell carcinoma: the 2010 update. Eur Urol 58: 398-406

Motzer RJ, Escudier B, Oudard S, Hutson TE, Porta C, Bracarda S, Grunwald V, Thompson JA, Figlin RA, Hollaender N, Kay A, Ravaud A (2010) Phase 3 trial of everolimus for metastatic renal cell carcinoma: final results and analysis of prognostic factors. Cancer 116: $4256-4265$

Motzer RJ, Escudier B, Oudard S, Hutson TE, Porta C, Bracarda S, Grunwald V, Thompson JA, Figlin RA, Hollaender N, Urbanowitz G, Berg WJ, Kay A, Lebwohl D, Ravaud A, for the RECORD-1 Study Group (2008) Efficacy of everolimus in advanced renal cell carcinoma: a doubleblind, randomised, placebo-controlled phase III trial. Lancet 372: 449-456

Motzer RJ, Hutson TE, Tomczak P, Michaelson MD, Bukowski RM, Rixe O, Oudard S, Negrier S, Szczylik C, Kim ST, Chen I, Bycott PW, Baum CM, Figlin RA (2007) Sunitinib versus interferon alfa in metastatic renal-cell carcinoma. $N$ Engl J Med 356: 115-124

National Cancer Institute (2006) Common terminology criteria for adverse events v3.0 (CTCAE). National Cancer Institute Web site. http:// ctep.cancer.gov/reporting/ctc_v30.html accessed on 24 October 2011

National Comprehensive Cancer Network (2012) NCCN Clinical Practice Guidelines in Oncology: Kidney Cancer. V.1.2012. National Comprehensive Cancer Network Web site. http://www.nccn.org accessed on 2 February 2012

Oudard S, Elaidi RT (2012) Sequential therapy with targeted agents in patients with advanced renal cell carcinoma: optimizing patient benefit. Cancer Treat Rev, http://dx.doi.org/10.1016/j.ctrv.2011.12.009

Porta C, Ostanto S, Ravaud A, Climent MA, Vaishampayan U, White DA, Creel P, Dickow B, Fischer P, Gornell SS, Meloni F, Motzer RJ (2011b) Management of adverse events associated with the use of everolimus in patients with advanced renal cell carcinoma. Eur J Cancer 47: 1287-1298
Porta C, Paglino C, Imarisio I, Canipari C, Chen K, Neary M, Duh MS (2011a) Safety and treatment patterns of multikinase inhibitors in patients with metastatic renal cell carcinoma at a tertiary oncology center in Italy. BMC Cancer 11: 105

Ravaud A (2011) Treatment-associated adverse event management in the advanced renal cell carcinoma patient treated with targeted therapies. Oncologist 16(Suppl 2): $32-44$

Rini BI, Escudier B, Tomczak P, Kaprin A, Szcylik C, Hutson TE, Michaelson MD, Gorbunova VA, Gore ME, Rusakov IG, Negrier S, Ou YC, Castellano D, Lim HY, Uemura H, Tarazi J, Cella D, Chen C, Rosbrook B, Kim S, Motzer RJ (2011) Comparative effectiveness of axitinib versus sorafenib in advanced renal cell carcinoma (AXIS): a randomized phase 3 trial. Lancet 378: 1931 - 1939

Rini BI, Michaelson MD, Rosenberg JE, Bukowski RM, Sosman JA, Stadler WM, Hutson TE, Margolin K, Harmon CS, DePrimo SE, Kim ST, Chen I, George DJ (2008) Antitumor activity and biomarker analysis of sunitinib in patients with bevacizumab-refractory metastatic renal cell carcinoma. J Clin Oncol 26: $3743-3748$

Sternberg CN, Davis ID, Mardiak J, Szczylik C, Lee E, Wagstaff J, Barrios CH, Salman P, Gladkov OA, Kavina A, Zarba JJ, Chen M, McCann L, Pandite L, Roychowdhury DF, Hawkins RE (2010) Pazopanib in locally advanced or metastatic renal cell carcinoma: results of a randomized phase III trial. J Clin Oncol 28: $1061-1068$

Therasse P, Arbuck SG, Eisenhauer EA, Wanders J, Kaplan RS, Rubinstein L, Verweij J, Van Glabbeke M, van Oosterom AT, Christian MC, Gwyther SG (2000) New guidelines to evaluate the response to treatment in solid tumors. J Natl Cancer Inst 92: 205-216

White DA, Camus P, Endo M, Escudier B, Calvo E, Akaza H, Uemura H, Kpamegan E, Kay A, Robson M, Ravaud A, Motzer RJ (2010) Noninfectious pneumonitis after everolimus therapy for advanced renal cell carcinoma. Am J Respir Crit Care Med 182: $396-403$

This work is published under the standard license to publish agreement. After 12 months the work will become freely available and the license terms will switch to a Creative Commons Attribution-NonCommercial-Share Alike 3.0 Unported License. 